\title{
Correction to: Characterizing Trophic State in Tropical/Subtropical Reservoirs: Deviations among Indexes in the Lower Latitudes
}

\author{
Davi Gasparini Fernandes Cunha $\mathbb{D}^{1} \cdot$ Nícolas Reinaldo Finkler $^{1} \cdot$ Marta Condé Lamparelli $^{2}$. \\ Maria do Carmo Calijuri ${ }^{1} \cdot$ Walter K. Dodds $^{3} \cdot$ Robert E. Carlson $^{4}$
}

Published online: 9 October 2021

(c) Springer Science+Business Media, LLC, part of Springer Nature 2021

Correction to: Environmental Management (2021) 68:491-504 https://doi.org/10.1007/s00267-021-01521-7

The original version of this article unfortunately contained a mistake. In this article, the citation information was incorrectly given as "In general, these latter studies were carried out in shallow and very shallow lakes (e.g., Jones and Bachmann 1976; Seip et al. 2000), where light limitation is less likely." but it should have been "In general, these latter studies were carried out in shallow and very shallow lakes (e.g., sub datasets from Phillips et al. 2008, Seip et al. 2000), where light limitation is less likely." The reference citation has now been corrected.

The original article has been corrected.

The original article can be found online at https://doi.org/10.1007/ s00267-021-01521-7.

Davi Gasparini Fernandes Cunha

davig@sc.usp.br

1 Departamento de Hidráulica e Saneamento, Escola de Engenharia de São Carlos, Universidade de São Paulo, São Carlos, SP, Brazil

2 Companhia Ambiental do Estado de São Paulo, São Paulo, SP, Brazil

3 Division of Biology, Kansas State University, Manhattan, KS, USA

4 Kent State University, Kent, OH, USA 